Original Article

\title{
A CLINICAL STUDY OF INCIDENCE AND DISTRIBUTION AND CO- RELATING FACTORS OF CLEFT LIP AND CLEFT PALATE AMONG KARNATAKA \& KERALA POPULATION
}

\section{Soumi Samuel ${ }^{1}$, B. Rajendra Prasad ${ }^{2}$, Suchetha Kumari ${ }^{3}$, S. Sandeep Tejaswi ${ }^{4}$ \& Sanal T.S \\ ${ }^{1}$ Reader, ${ }^{2}$ Principal, ${ }^{4}$ Resident, Department of Oral \& Maxillofacial Surgery,}

A.B. Shetty Memorial Institute of Dental Sciences, ${ }^{3}$ Professor, Department of Biochemistry, ${ }^{5}$ Statistician, Department of Humanities \& Social Sciences, K. S. Hegde M edical Academy Nitte University, Mangalore - 575 018, Karnataka, India.

\section{Correspondence :}

Soumi Samuel

Reader, Department of Oral \& M axillofacial Surgery, A.B. Shetty Memorial Institute of Dental Sciences Nitte University, Mangalore - 575 018, Karnataka, India.

Mobile : +919880834711 E-mail : soumisamuel@gmail.com

\begin{abstract}
:
The aim of this prospective study is to determine the incidences of cleft lip and palate in Karnataka \& Kerala population. It also highlights a part of embryological aspect and theories that help to correlate and understand the incidence of the congenital anomaly. This prospective study were conducted in 1000 patients having cleft lip and palate deformities and classified, incidences and types of patterns of occurrences were statistically analysed. It was observed that incidences of Cleft lip and palate is more common in males were $51.9 \%$ and that of Cleft palate is more prevelant in females were - $48.1 \%$
\end{abstract}

Keywords: Teratogenic drugs, Clefting, Congenital, Philtrum.

\section{Introduction:}

Cleft of upper lip and palate are most common major congenital craniofacial abnormality noted 1 in 700 births. Although inheritance may play a role, cleft lip and palate is not considered a single gene disease but are multifactorial etiology with potential contributing factors, including chemical exposures, radiation, maternal hypoxia, teratogenic drugs, nutritional deficiencies especially folic acid, physical obstruction or genetic influences. One prevailing theory states the process of clefting as threshold in which multiple etiological factors come together to raise individual above which the mechanism of fusion fails. ${ }^{1}$

The orofacial clefts are the congenital deformities, which manifest at birth. Any disturbance during the embryological formation Access this article online Quick Response Code

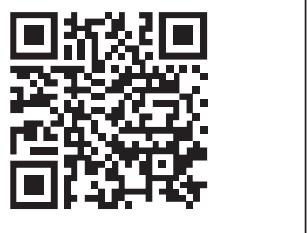

cleft palate in India among South Indian population are available, however international figures are available. As analysed by Fogh and Anderson 1942(Denmark) cited 1:655 frequency R.H. Ivy (1963) from the state of Pennsylvania, USA quoted the incidence of cleft occurrence to be 1:760.

In India survey conducted by Vellore reported the incidence of cleft lip and cleft palate in the regional population as 1:639. It is now well accepted, that in cases prealveolar clefts, unilateral clefts (75\%) are more common than the bilateral clefts $(25 \%)$. In cases with unilateral prealveolar clefts, left sided cleft is more common than the right side. About 3 to $5 \%$ of cleft lip and palates may be associated with congenital deformities of the other parts of the body. $50 \%$ of deformities are combined clefts of the lip and palate. About $25 \%$ are bilateral ones.

The purpose of study is to evaluate the incidences and occurrences and patterns of distribution of cleft lip and palate cases. This prospective study comprises of 1000 cases randomly taken from Karnataka and Kerala population and categorized to standard classification ${ }^{1}$, there by determining the anatomical location specification 
and percentage of occurrences of cleft lip and palate among subjects.

\section{Embryology:}

In the development of cleft lip and palate, intercontact and fusion between maxillary processes and median nasal process is normal. The critical problem is failure of LNP to make contact with MNP.The initial MXP-MNP fusion remains intact in the early stages of cleft,but in $90 \%$ it ruptures later. Clefts of the secondary palate is due to failure of palatine shelves to fuse together. Medial Nasal Process forms the middle portion of nose, the middle portion of upper lip called philtrum, middle portion of premaxilla carries four incisiors and the entire primary palate. Lateral Nasal Process forms the ala of nose. Premaxillary segment is continuous with nasal septum formed by frontal prominences. Thus maxillary process -

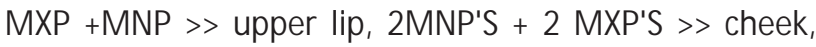
maxilla, zygoma and secondary palate.

\section{Two theories:}

1. Theory of Dursy-His (1931 San Franciso):- put forward the hypothesis of failure of fusion of various facial processes. In fact it sounded a very convincing theory to explain the formation of various degrees of unilateral and bilateral clefts and even the rare midline upper and lower clefts. This explained the presence of Simonart's band in an incomplete cleft lip.The term process implies finger like projections of tissue and fusion imples that the projections meet, their epithelial walls disappear and then they grow together. It has now been proved that this is not the case. It is realized that it is not a question of processes but of localized prominence.

2. Theory of failure of mesodermal migration:Fleischmann, a zoology professor (Germany 1910) stated that cleft palate is the arrest of the disappearance of epithelial membrane which remains intact not penetrated by the adjacent mesoderm. This theory was further endorsed by Victor Veau(1935) and supported by Stark (1954).M esodermal theory proposes that as the oral and nasal cavities deepen, there is an increase in the sizes of facial prominences due to the penetration of mesoderm. As more mesoderm enters the area, the bulging increases so that what was used to be a wall of tissue with ectoderm on one side and endoderm on the other side is transformed into prominences and grooves depending on the amount of mesoderm between the two epithelial layers. Failure of sufficient mesoderm to migrate into a specific area is responsible for the persistence of a groove. With consequent epithelial breakdown the persistent groove gives way to an established cleft. This the most accepted theory.

\section{Aim of study :}

To determine the incidences and distribution in regional population having cleft lip and cleft palate.

\section{Materials and Methods:}

Population data for incidences of clefts were assembled from Dept. Oral and Maxillofacial Surgery, A.B. Shetty Memorial Institute of Dental Sciences, DeralakatteM angalore. The collected data were categorized into three groups - cleft lip, cleft lip and palate, cleft palate alone. Also they were sub classified as unilateral/bilateral/left/right/ complete/incomplete from South Indian Population from Karnataka \&Kerala State. Over all sample size selected was One thousand (1000), of these males were $51.9 \%$, females $48.1 \%$.

Chi-Square test was applied to evaluate the goodness of fit of the observed data to expected data of occurrences and the results are given in table 1

Table : 1

\begin{tabular}{|c|c|c|c|c|c|c|c|c|c|c|c|c|c|c|}
\hline & \multicolumn{6}{|c|}{ Cleft Lip } & \multicolumn{6}{|c|}{ Cleft Lip and Palate } & \multicolumn{2}{|c|}{ Cleft Palate } \\
\hline & \multicolumn{4}{|c|}{ Unilateral } & \multicolumn{2}{|c|}{ Bilateral } & \multicolumn{4}{|c|}{ Unilateral } & \multicolumn{2}{|c|}{ Bilateral } & \multirow[t]{3}{*}{ Complete } & \multirow[t]{3}{*}{ Incomplete } \\
\hline & \multicolumn{2}{|c|}{ Complete } & \multicolumn{2}{|c|}{ Incomplete } & \multirow[t]{2}{*}{ Complete } & \multirow[t]{2}{*}{ Incomplete } & \multicolumn{2}{|c|}{ Complete } & \multicolumn{2}{|c|}{ Incomplete } & \multirow[t]{2}{*}{ Complete } & \multirow[t]{2}{*}{ Incomplete } & & \\
\hline & Right & Left & Right & Left & & & Right & Left & Right & Left & & & & \\
\hline Male & 48 & 68 & 4 & 7 & 25 & 3 & 47 & 147 & 12 & 11 & 55 & 4 & 87 & 1 \\
\hline Female & 46 & 62 & 1 & 7 & 19 & 1 & 51 & 135 & 8 & 8 & 47 & 6 & 85 & 5 \\
\hline $\begin{array}{l}\text { Chi square } \\
\text { P value }\end{array}$ & $0 . \varepsilon$ & 54 & 0.33 & & & $31 *$ & $<0.00$ & $01 * *$ & 0.8 & 94 & & 513* & 0.2 & $11 *$ \\
\hline
\end{tabular}




\section{Results:}

1. Among 1000 patients surveyed 291 patients constituted cleft lip constituted $29.1 \%$ cases. Out of which unilateral cases accounted for $24.3 \%$ and bilateral $4.8 \%$. In this study we further categorized into Site prevelances and sex prevalences. Cleft lip among males unilateral complete right side more than females constituting $4.8 \%$ and $4.6 \%$ patients respectively. Bilateral cases accounted for 48 cases with males being $2.5 \%$ and females $1.9 \%$ subjects.

2. Cleft lip and palate accounted for $53.1 \%$ out of 1000 subjects. Unilateral complete cases accounted maximum number of patients of $38 \%$ out of which the right side $9.8 \%$ subjects and left side prevalence's was more accounting 282 subjects. Incomplete cases right side were $0.2 \%$ and left were $1.9 \%$ of subjects. In this study bilateral cases were total of 112 we further categorized as complete and incomplete accounting for $10.2 \%$ and $1 \%$ respectively.

3. Cleft palate accounts a total of $17.8 \%$,complete cases constituted of 172 of which males were noted to be $8.7 \%$ and females $8.5 \%$ further analysis revealed that complete cleft palate cases were more in number and incomplete palate cases constituted 6 subjects of which males were noted to be 1 and females were noted to be 5 . As per the literature survey incomplete cleft palate cases is a rare entity.

From the above analysis depicting the incidences of Cleft lip and palate is $15.4 \%$.

From above analysis it can be inferred that the comparative incidences of cleft lip and palate cases accounts over all $15.4 \%$ cases of which males unilateral cleft lip was noted to be $12.7 \%$, CLP - $20.8 \%$, CP $-8.8 \%$, B/L, CL- 2.8\% , CLP- 5.9\%.

Female population analysis revealed that unilateral cleft lip constituted $11.6 \%$, cleft lip and palate $-20.2 \%$ cleft palate - $9 \%$ that of bilateral cases constituted cleft lip $2 \%$ and cleft lip and palate only $5.3 \%$.
Figure 1 : Distribution of cleft lip and palate complete and incomplete among study subjects.

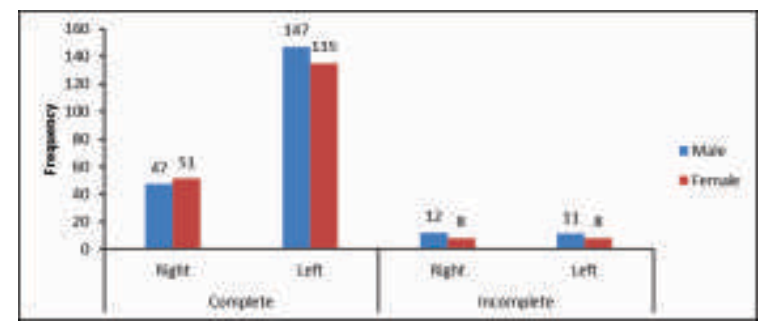

Figure 2 : Distribution of ratio between the unilateral complete to incomplete among the study subjects.

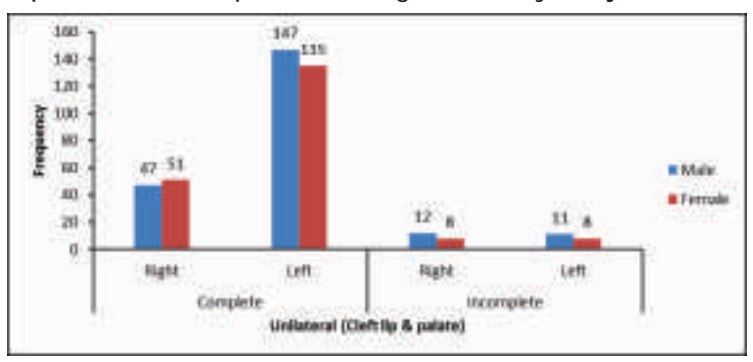

Figure 3 : Distribution of ratio between the bilateral complete to incomplete among the study subjects

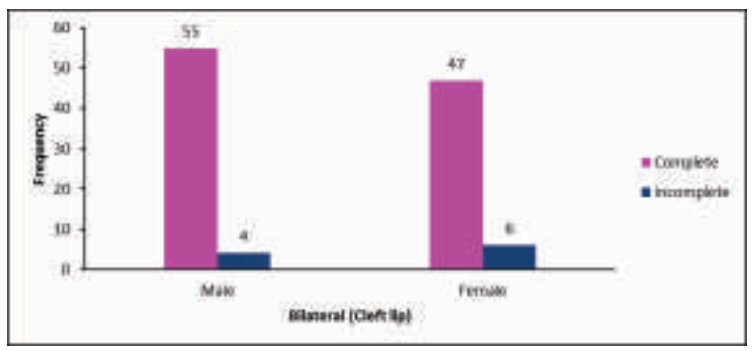

Figure 4 : Distribution of bilateral cleft lip and palate among the subjects

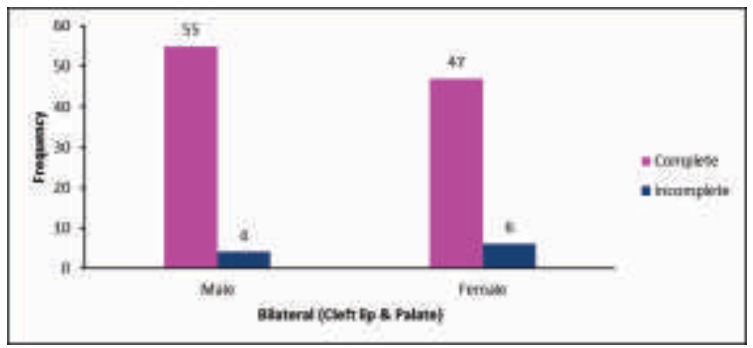

Figure 5 : Distribution of cleft palate with respect to gender among the subjects.

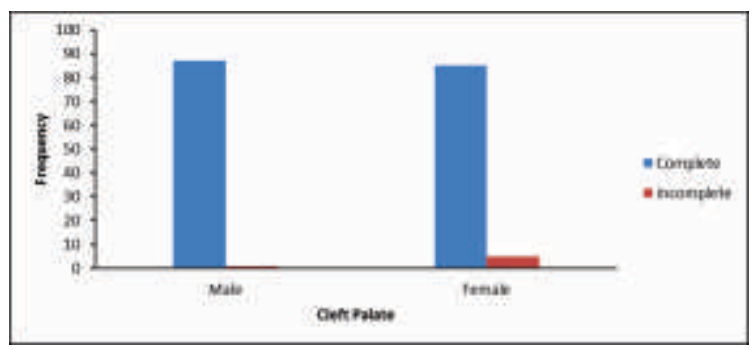




\section{Discussion :}

The above mentioned study indicates that the more frequent occurrences of cleft lip and palate cases affects more of male subjects $51.9 \%$ than females $48.1 \%$, cleft lip deformity is more common in males whereas cleft palate deformity is more common in females among Karnataka and Kerala population being $29.1 \%$ out of 1000 subjects unilateral cases accounting for $24.3 \%$, bilateral cases $4.8 \%$ from above study indicates that unilateral cleft lip cases accounting of $4.8 \%$ in males than in females. Cleft lip and palate accounts for $53.1 \%$ cases out of 1000 subject's unilateral occurrences noted on right side is more $3.8 \%$ compared to left side $9.8 \%$. Incomplete cleft lip and palate cases accounted least number of $0.2 \%$ to $1.9 \%$.Cleft palate were total represented $17.8 \%$ of 1000 subjects with males constituting $8.7 \%$ females $8.5 \%$ it revealed not much differences noted in occurrence of cleft palate among males and female subjects.

\section{Acknowledgements:}

Dr. Vikram Shetty - Director - Department of Craniofacial

\section{References:}

1. M M Tolarova, Cervenka J- classification and birth prevalence of orofacial clefts.J Craniofacial Surgery 32:7,423-427: 1998.

2. L Capelozza, SM Tanigchi - The craniofacial morphology of adult unoperated cleft lip and palate. J Craniofacial Surgery - 30:4,376-381, 1993.

3. J Milerad, O Larson, C Hagberg - Associated malformations in infants with cleft lip and palate a prospective population based study.J Paediatrics 100;2, 180-186, 1997.

4. LG Farkas, K Hajnis, JC Posnik - Anthromometric and anthroposcopic findings of the nasal and facial region in cleft patients before and after lip repair.J Craniofacial Surg 30;1-12, 1993.

5. JCM urray - Clinical Genetics, Gene and environmental causes of cleft lip and palate.Wiley Online Library-2002
Surgery - Nitte M eenakshi Institute, K. S. Hegde Medical Academy, Nitte University.

\section{Conclusion :}

The occurrences of cleft lip and cleft palate continue to plague mankind. A precise identification of factor is difficult owing to its multifactorial etiologies. In view of above study it can be deduced that different types of cleft anomalies and its locations can occur in subjects irrespective of sex in varied anatomical locations. Each type of cleft anomaly has its own unique clinical characteristic feature that the clinician should distinguish and modify treatment plan accordingly. Although treatment for a cleft lip and cleft palate may extend over several years and require several phases of surgical treatments depending upon the involvement, most subjects affected by this condition can achieve normal appearance, speech and function thereby reducing social and psychological stigmata for these subjects. 